\title{
Effect of Gamma Radiation on Properties of a Calcium Phosphate-Calcium Sulfate Composite Cement
}

\author{
Chang-Keng Chen ${ }^{1, * 1}$, Chien-Ping Ju ${ }^{1}$, Jing-Wei Lee ${ }^{2}$ and Jiin-Huey Chern Lin ${ }^{1, * 2}$ \\ ${ }^{1}$ Department of Materials Science and Engineering, National Cheng-Kung University, 70101, Tainan city, Taiwan, R. O. China \\ ${ }^{2}$ Division of Plastic and Reconstructive Surgery, Department of Surgery, National Cheng-Kung University Medical College and Hospital, \\ 138 Sheng-Li Road, 70428, Tainan city, Taiwan, R. O. China
}

\begin{abstract}
The present study investigates $\gamma$-radiation effect on structure and selected properties of a tetracalcium phosphate (TTCP)/dicalcium phosphate anhydrous (DCPA)/calcium sulfate hemihydrate (CSH) cement immersed in Hanks' solution. The results indicate that, at a dosage of $25 \mathrm{kGy}$, the working and setting times of the cement paste derived from $\gamma$-ray-sterilized TTCP/DCPA/CSH powder did not change significantly. At $50 \mathrm{kGy}$ or higher, however, both significantly decreased. A dose of $25 \mathrm{kGy}$ caused the 1-d compressive strength of the cement to decrease by $15 \%$. Further increases in $\gamma$-ray dose did not further change the strength. After immersion for 1 day, the pH values of all non-sterilized and sterilized samples were in the range of 7.6-8.0. The XRD patterns of non-sterilized and sterilized powders were substantially similar. After immersion for 1 day, TTCP phase was still distinguishable, while CSH peaks were largely diminished and apatite phase became dominant. The non-sterilized sample had a significantly higher apatite conversion ratio than those of $\gamma$-ray-sterilized samples. The average 1 -d porosity values of all sterilized and non-sterilized samples were similar (31-33\%). The $\gamma$-ray-sterilized cement samples had coralline type morphology with numerous tiny apatite crystals and micropores. Compared to the sterilized samples, the non-sterilized cement showed a smoother and denser morphology. [doi:10.2320/matertrans.M2013007]
\end{abstract}

(Received January 8, 2013; Accepted March 26, 2013; Published May 17, 2013)

Keywords: $\gamma$-ray, calcium phosphate, calcium sulfate, cement

\section{Introduction}

Bioresorbable bioceramic has become one of the most promising bone substitute materials nowadays. ${ }^{1-4)}$ Calcium phosphate and calcium sulfate are two typical such bioresorbable materials. ${ }^{5,6)}$ Furthermore, due to its unique injectable feature, calcium phosphate cement (CPC) can be used in bonding, filling, and repairing damaged natural bone in orthopedic, dental, maxillofacial and other medical applications via minimally invasive procedures. ${ }^{7-9)}$

There are four common sterilization methods: autoclave, gas plasma, ethylene oxide and irradiation (e.g., gamma ray) for surgical practices. Each method has its inconveniencies in treating CPC powders. For example, ethylene oxide gassterilization could leave residues of ethylene oxide within pores. The residual toxicity by ethylene oxide is inevitable. ${ }^{10)}$ Autoclave sterilizes materials by steam, while moisture and/or heat could induce phase transitions of the material. ${ }^{11)}$ Among the various methods, $\gamma$-radiation seems so far to be the most reliable one for sterilizing CPC powders if its dose is properly selected.

Although a wide range (about 20-90 kGy) of $\gamma$-ray dose has been used in sterilizing various kinds of CPC powders, ${ }^{12-15)}$ study of $\gamma$-ray effect on the structure and properties of CPC powders and their derived cements is still limited. One earlier study from the present authors' laboratory revealed that the morphology and properties of a tetracalcium phosphate (TTCP)/dicalcium phosphate anhydrous (DCPA)-derived CPC were related to the dose of $\gamma$-radiation on the biphasic CPC powder. ${ }^{16)}$

Most popularly-used calcium phosphates exhibit relatively low bioresorption rates, ${ }^{6}$ while most calcium sulfates

\footnotetext{
${ }^{* 1}$ Graduate Student, National Cheng-Kung University

${ }^{* 2}$ Corresponding author, E-mail: chernlin9@gmail.com
}

demonstrate relatively low mechanical strengths and dissolution rates being too high, ${ }^{5}$ that may not allow new bone cells to effectively grow into a bone cavity. ${ }^{9}$ It seems logical to combine calcium phosphate and calcium sulfate into a composite formula and expect the inherent advantages from each component. A series of TTCP/DCPA/calcium sulfate hemihydrate $(\mathrm{CSH})$ cement had been investigated in previous studies, ${ }^{17-19)}$ including their phases, structure and properties changed in Hanks' solution. The results showed that working/setting times (curing time) generally increased and strength decreased with increasing the CSH content. Nevertheless, the effects of radiation exposure on properties of TTCP/DCPA/CSH cement remain unknown. The present study continues to investigate the effect of $\gamma$-radiation on the structure and selected properties of a triphasic TTCP/ DCPA/CSH cement recently developed in the authors' laboratory.

\section{Materials and Methods}

The TTCP powder was fabricated in-house using the method suggested by Brown and Epstein. ${ }^{20)}$ Appropriate amounts of in-house prepared TTCP and commercial DCPA powders were uniformly mixed, followed by mixing with an appropriate amount of CSH powder. The resultant TTCP/ DCPA/CSH powder mixture was $\gamma$-ray-sterilized at China Biotech Co. (Taichung, Taiwan) with a series of different $\gamma$ ray doses $(25,50,75$ and $100 \mathrm{kGy})$ for the study. The $\gamma$-raysterilized TTCP/DCPA/CSH powder with a weight ratio of $4.14: 1.54: 1$ for each constituent (or a weight ratio of $85: 15$ for TTCP/DCPA: CSH) was mixed uniformly with a $0.6 \mathrm{M}$ $\left(\mathrm{NH}_{4}\right)_{2} \mathrm{HPO}_{4}$ setting solution with a $\mathrm{pH}$ value of 8.0 at a liquid/powder $(\mathrm{L} / \mathrm{P})$ ratio of $0.28 \mathrm{~cm}^{3} / \mathrm{g}$ to form a cement paste. 
After mixing for $1 \mathrm{~min}$, the cement paste was packed into a $6 \mathrm{~mm}$ dia., $12 \mathrm{~mm}$ deep cylindrical stainless steel mold under a pressure of $1.4 \mathrm{MPa}$ for $30 \mathrm{~min}$. After being removed from the mold, the hardened cement samples were immersed in Hanks' physiological solution ${ }^{21)}(\mathrm{pH}=7.4)$ at $37^{\circ} \mathrm{C}$ for 1 day. After immersion, samples were removed from the solution for compressive strength (CS) measurement while they were still wet. The CS testing was conducted according to ASTM 451-99a method using a desk-top mechanical tester (Shimadzu AG-10KNX, Tokyo, Japan) at a crosshead speed of $1.0 \mathrm{~mm} / \mathrm{min}$.

The working time of cement paste was determined by the time after that the cement paste was no longer workable. The setting time of cement paste was measured according to the standard method set forth in ISO 1566 for dental zinc phosphate cements. The cement is considered set when a $400 \mathrm{~g}$ weight loaded onto a Vicat needle with a $1 \mathrm{~mm}$ dia. tip fails to make a perceptible circular indentation on the surface of the cement. During measurement the cement was kept in a $50-70 \%$ relative humidity environment at $24^{\circ} \mathrm{C}$.

The early stage (during setting process) variation in $\mathrm{pH}$ value was determined using a $\mathrm{pH}$ meter (Suntex Instruments SP-2300, Taipei, Taiwan) that was embedded in the cement paste immediately after the powder and setting liquid were mixed. The first reading was taken at 2 min after mixing. Readings were taken every $1 \mathrm{~min}$ until $30 \mathrm{~min}$ post-mixing. The $\mathrm{pH}$ value of the Hanks' solution wherein the cement paste sample was immersed for one day was monitored using the same $\mathrm{pH}$ meter.

The porosity values of both non-sterilized and $\gamma$-raysterilized cement samples were measured according to ASTM C830-00 (2006) method. A one-way ANOVA method was used to evaluate the statistical significance of working/setting time, compressive strength, $\mathrm{pH}$ value and porosity. In all cases, the results were considered statistically different with $\mathrm{p}<0.05$.

The various phases of the cement under different conditions were analyzed using a Rigaku D-MAX B X-ray diffractometer (XRD) (Tokyo, Japan) with Ni-filtered CuKa radiation operated at $30 \mathrm{kV}$ and $20 \mathrm{~mA}$ at a scanning speed of $1 \% \mathrm{~min}$. Each phase was identified by comparing its characteristic peaks with data compiled in the JCPDS files. The XRD patterns used for calculating apatite ratios of the cement samples were obtained using a lower scanning speed $\left(0.5^{\circ} / \mathrm{min}\right)$ in the $2 \theta$ range from 24 to $30^{\circ}$. The apatite conversion ratios were calculated using the equation from Fukase et al., ${ }^{22)} \%$ Conversion $=1 / 2\left\{\mathrm{HA}_{\mathrm{d}} / \mathrm{HA}_{\infty}+[1-\right.$ $\left.\left.\left(\mathrm{DCPA}_{\mathrm{d}} / \mathrm{DCPA}_{0}\right)+1-\left(\mathrm{TTCP}_{\mathrm{d}} / \mathrm{TTCP}_{0}\right)\right] / 2\right\} \times 100$, where $\mathrm{DCPA}_{0}$ and $\mathrm{TTCP}_{0}$ are the peak areas of DCPA and TTCP in the TTCP/DCPA/CSH powder; $\mathrm{HA} \infty$ is the peak area of HA in the fully cured CPC (4 weeks in water); and $\mathrm{DCPA}_{d}$, $\mathrm{TTCP}_{d}$ and $\mathrm{HA}_{d}$ are the corresponding area values of the cement samples immersed in Hanks' solution for 1 day.

The microstructure of the cement under different conditions was examined using a ultrahigh resolution fieldemission scanning electron microscope (UHRFE-SEM) (Auriga, Zeiss, Germany) operated at $5 \mathrm{kV}$. The fracture surfaces were coated with a thin layer of gold using an ion sputtering system (JFC-1100, JEOL, Japan) to facilitate conducting of the samples being examined.

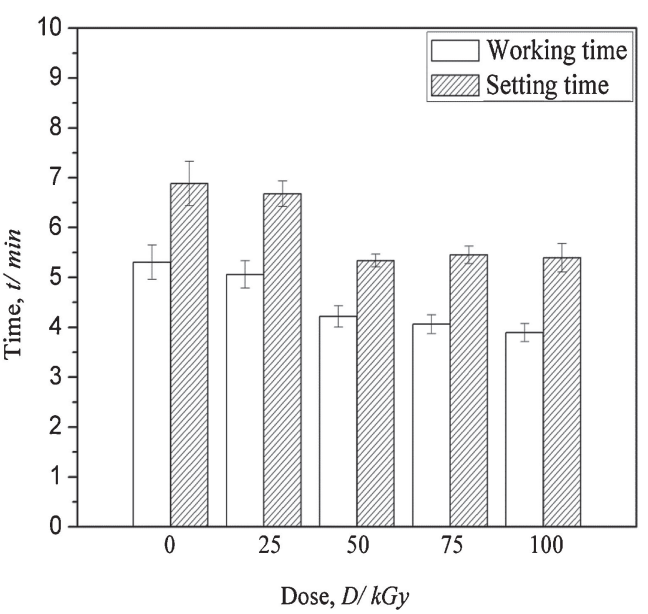

Fig. 1 Working time and setting time of TTCP/DCPA/CSH cement prepared from powders sterilized with different $\gamma$-ray doses.

\section{Results and Discussion}

\subsection{Radiation-induced changes in working time and setting time}

As indicated in Fig. 1, at a dosage of $25 \mathrm{kGy}$, the working time and setting time of the $\gamma$-ray-sterilized TTCP/DCPA/ $\mathrm{CSH}$ cement did not show significant changes, as compared to the non-sterilized cement $(\mathrm{p}>0.05)$. At a dosage of $50 \mathrm{kGy}$ or higher, however, the working time and setting time significantly decreased respectively from 5.5 and $7.0 \mathrm{~min}$ to 4.0 and $5.5 \mathrm{~min}(\mathrm{p}<0.05)$. According to an early study of Tsai et al., ${ }^{23)}$ the setting time of their $\gamma$-ray-sterilized TTCPderived CPC decreased significantly at higher doses (40$120 \mathrm{kGy}$ ) due to radiation-induced defects and/or preferential growth of apatite crystals. Same explanation may apply to the observed decrease in working/setting times in the present study. From a practical (cement handling) point of view, a $\gamma$ ray dose lower than $25 \mathrm{kGy}$ seems more desirable than that with higher doses (>50 kGy).

\subsection{Radiation-induced changes in compressive strength}

The variation in compressive strength of the TTCP/ DCPA/CSH cement with $\gamma$-ray dosage was demonstrated in Fig. 2. As indicated in the figure, the exposure of the cement powder to $\gamma$-ray of a dose of $25 \mathrm{kGy}$ caused the compressive strength of its derived hardened cement to significantly decrease by $15 \%$ (from 40 to $34 \mathrm{MPa}$ ). Further increases in $\gamma$ ray dose did not further change the compressive strength of the hardened cement in a significant way. This radiationinduced decrease in compressive strength is considered to be attributed to its lower apatite conversion ratio and relatively porous morphology, as will be described later.

\subsection{Radiation-induced changes in $\mathrm{pH}$ value}

The $\gamma$-ray-induced changes in $\mathrm{pH}$ value of the TTCP/ DCPA/CSH cement during setting process were shown in Fig. 3. As can be seen from the figure, quickly after mixing of powder and setting solution (with a starting $\mathrm{pH}$ value of 8.0 ), the $\mathrm{pH}$ values of both sterilized and non-sterilized samples slightly but consistently dropped to 7.7-7.9 due to quick dissolution of CSH phase. ${ }^{6}$ Following the initial drops, 


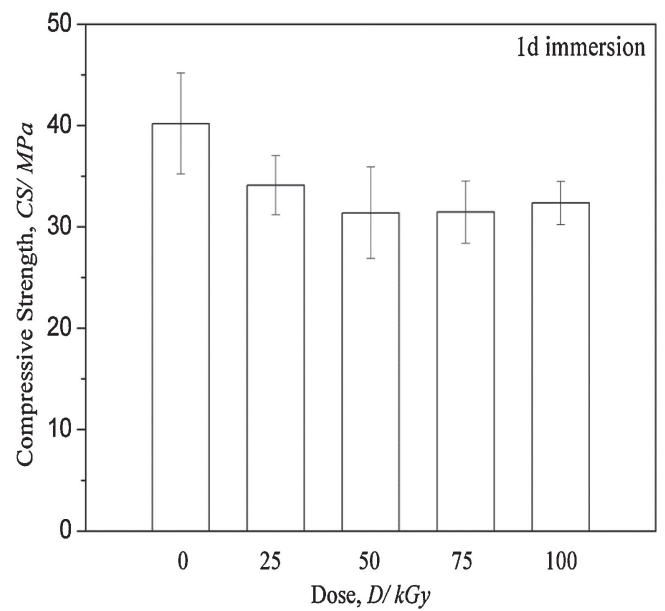

Fig. 2 Compressive strength of TTCP/DCPA/CSH cement prepared from powders sterilized with different $\gamma$-ray doses.

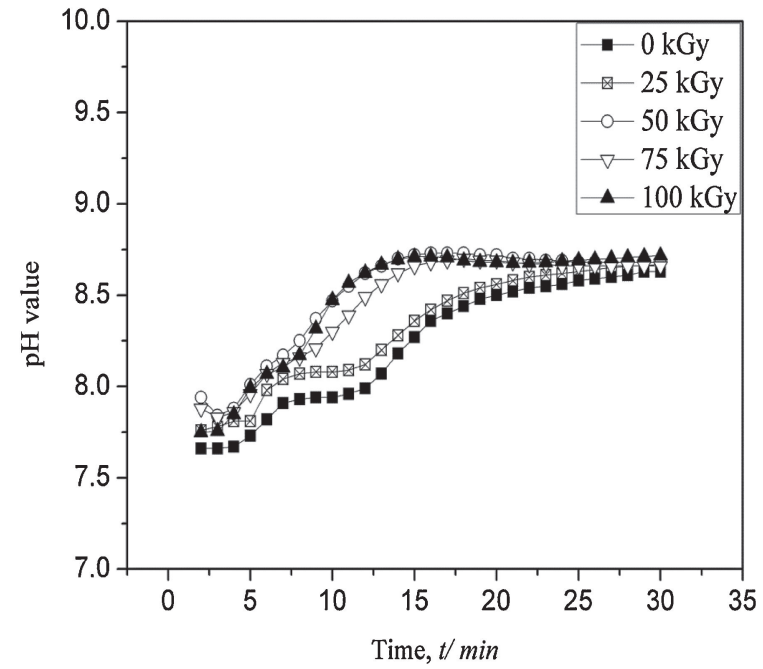

Fig. $3 \mathrm{pH}$ values of TTCP/DCPA/CSH cement prepared from powders sterilized with different $\gamma$-ray doses during setting process.

the $\mathrm{pH}$ values of all samples (sterilized and non-sterilized) continued to increase with time primarily due to the early dissolution of TTCP in phosphate-containing solution causing increase in $\mathrm{pH}$ value. ${ }^{24)}$ Compared to those of nonsterilized and $25 \mathrm{kGy}$-sterilized samples, the $\mathrm{pH}$ values of samples with higher doses increased faster, especially after mixing for about $10-15 \mathrm{~min}$. After about $20 \mathrm{~min}$, the $\mathrm{pH}$ values of all cement samples derived from both non-sterilized and $\gamma$-ray-sterilized TTCP/DCPA/CSH powders became stabilized within a narrow range of about $8.6-8.8$. This is probably due to the limited supply of the setting solution (due to a fixed powder/liquid ratio) during hardening process that did not allow the reaction (formation of apatite) to complete and thus a $\mathrm{pH}$ plateau was reached.

Figure 4 shows pH values of Hanks' solution wherein sterilized and non-sterilized cement samples were immersed for 1 day. As can be seen from the figure, after immersion in Hanks' solution for 1 day, the $\mathrm{pH}$ values of all cement samples (both sterilized and non-sterilized) fell within a range of about 7.6-8.0. One-way ANOVA analysis indicated that the differences among samples with different $\gamma$-ray doses were not significantly $(\mathrm{p}>0.05)$.

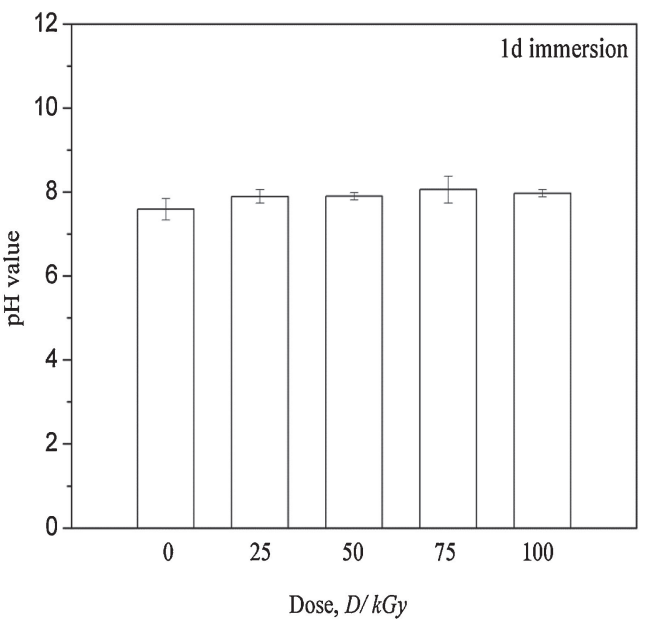

Fig. 4 pH values of Hanks' solution wherein TTCP/DCPA/CSH cement prepared from powders sterilized with different $\gamma$-ray doses was immersed for 1 day.

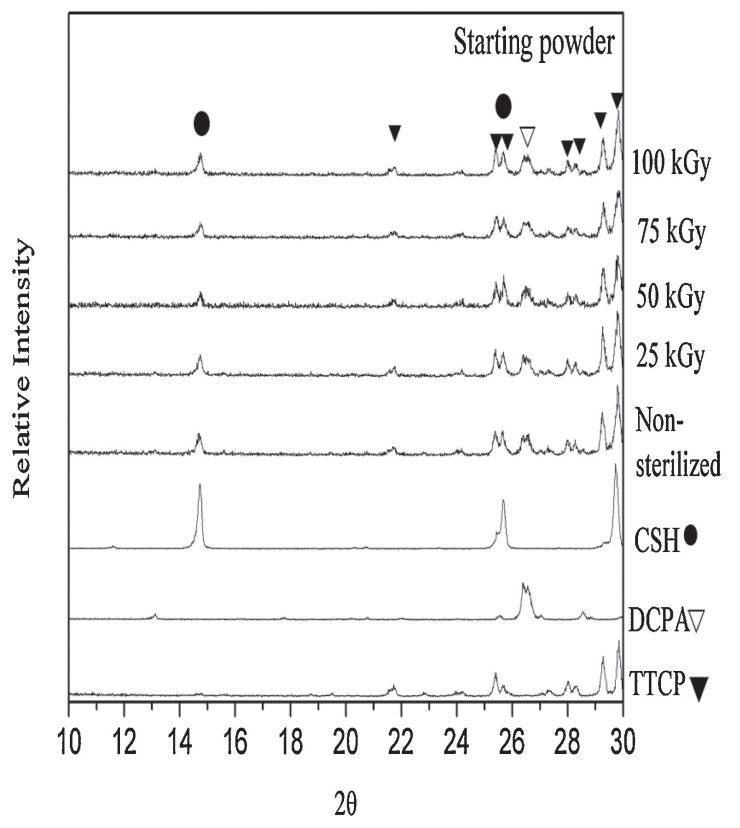

Fig. 5 XRD patterns of TTCP/DCPA/CSH powders sterilized with different $\gamma$-ray doses.

\subsection{Radiation-induced changes in phases and micro- structure}

The XRD patterns of the TTCP/DCPA/CSH powders sterilized with different $\gamma$-ray doses and their derived hardened cement samples immersed in Hanks' solution for 1 day are shown in Figs. 5 and 6, respectively. As can be seen from Fig. 5, the XRD patterns of non-sterilized and sterilized powders were substantially similar. No noticeable differences were observed even in the powder sterilized with dosage as high as $100 \mathrm{kGy}$.

As shown in Fig. 6(a), after the hardened cement sample was immersed in Hanks' solution for 1 day, the characteristic peaks of TTCP phase were still well distinguishable, but CSH peaks were largely diminished, indicating a quick dissolution process of $\mathrm{CSH}$ in the solution. ${ }^{6}$ In the meanwhile, the apatite/HA phase became dominant. The substantial absence of calcium sulfate dihydrate (CSD) peaks in the XRD 

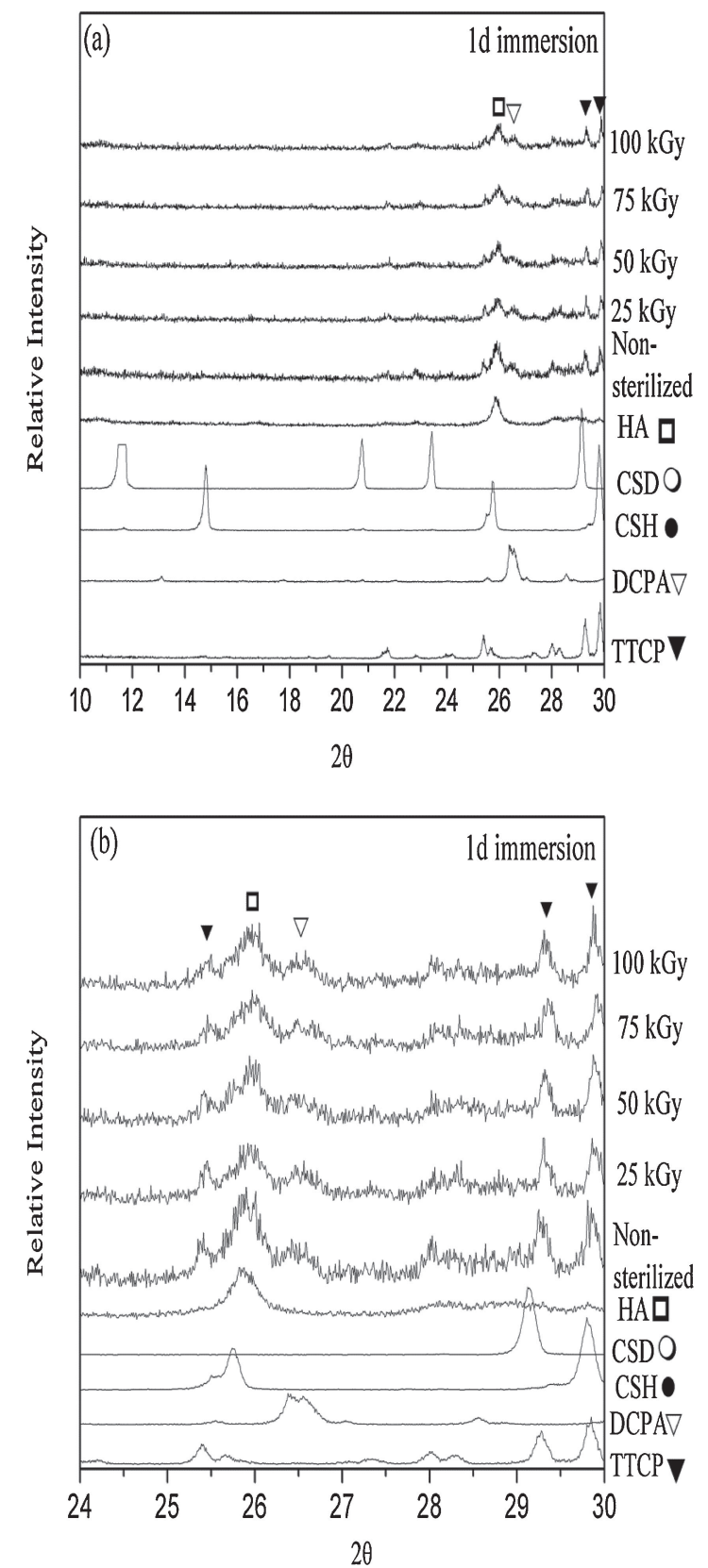

Fig. 6 XRD patterns of TTCP/DCPA/CSH cement prepared from powders sterilized with different $\gamma$-ray doses immersed in Hanks' solution for 1 day. (a) Scanning speed $=1 \% / \mathrm{min}$; (b) scanning speed $=0.5^{\circ} / \mathrm{min}$.

patterns is considered due to its relatively quick dissolution after it was formed by the hydration of CSH in the solution.

XRD patterns with a lower scanning rate (Fig. 6(b)) were used to determine the apatite conversion ratios of the various samples by applying the method described in "Materials and Methods." As shown in Fig. 7, the $\gamma$-ray-induced changes in TTCP/DCPA-HA apatite conversion ratio had a similar trend to that in compressive strength. The non-sterilized sample had a significantly higher apatite conversion ratio $(74 \%)$ than those of $\gamma$-ray-sterilized samples (64-67\%), indicating that the exposure of the cement powder to $\gamma$-ray had slowed down TTCP/DCPA-HA phase transformation process. Although the reason is not yet clear, one possible explanation is that the $\gamma$-ray-induced apatite phase on the powder surface ${ }^{23)}$ may somewhat hinder the TTCP/DCPA-HA phase transformation.

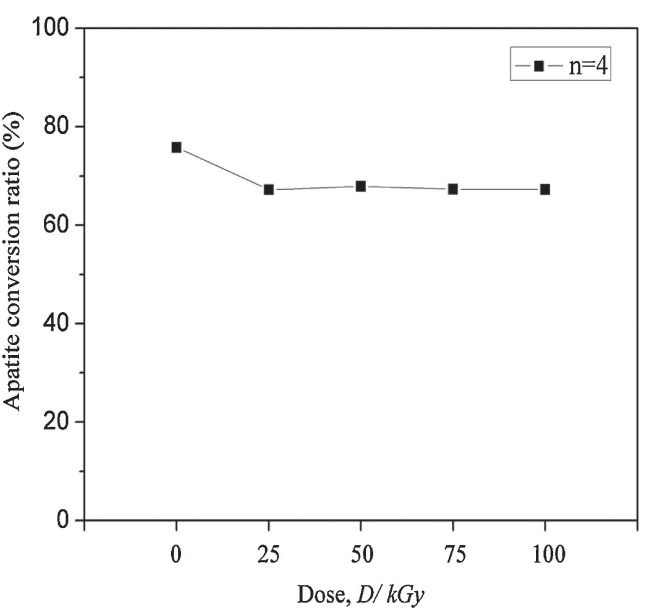

Fig. 7 Apatite conversion ratios of TTCP/DCPA/CSH cement prepared from powders sterilized with different $\gamma$-ray doses.

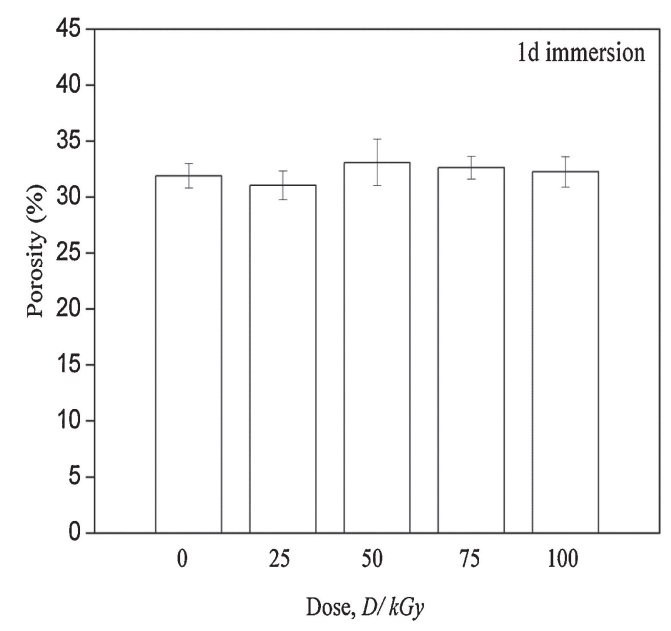

Fig. 8 Porosity values of TTCP/DCPA/CSH cement prepared from powders sterilized with different $\gamma$-ray doses immersed in Hanks' solution for 1 day.

Within the present dose range $(25-100 \mathrm{kGy})$, nevertheless, the $\gamma$-ray-induced change in apatite conversion ratio was not sensitive to the dose level. The higher TTCP/DCPA-HA conversion rate of non-sterilized cement may help explain its aforementioned higher 1d compressive strength. Ishikawa et $a .^{25)}$ also suggested that the formation of HA was crucial to the mechanical strength of their TTCP/DCPA-derived CPC.

Figure 8 shows porosity values of cement samples prepared from TTCP/DCPA/CSH powders sterilized with different $\gamma$-ray doses immersed in Hanks' solution for 1 day. As can be seen from the figure, after immersion in Hanks' solution for 1 day, the average porosity values of all cement samples (sterilized and non-sterilized) were in a range of $31-33 \%$ and did not show significant differences among them $(\mathrm{p}>0.05)$.

Demonstrated in Fig. 9 are typical fracture surface morphologies of TTCP/DCPA/CSH cement prepared from powders sterilized with different $\gamma$-ray doses immersed in Hanks' solution for 1 day. As can be seen from the scanning electron micrographs, the $\gamma$-ray-sterilized cement samples had coralline type morphology with numerous tiny apatite 

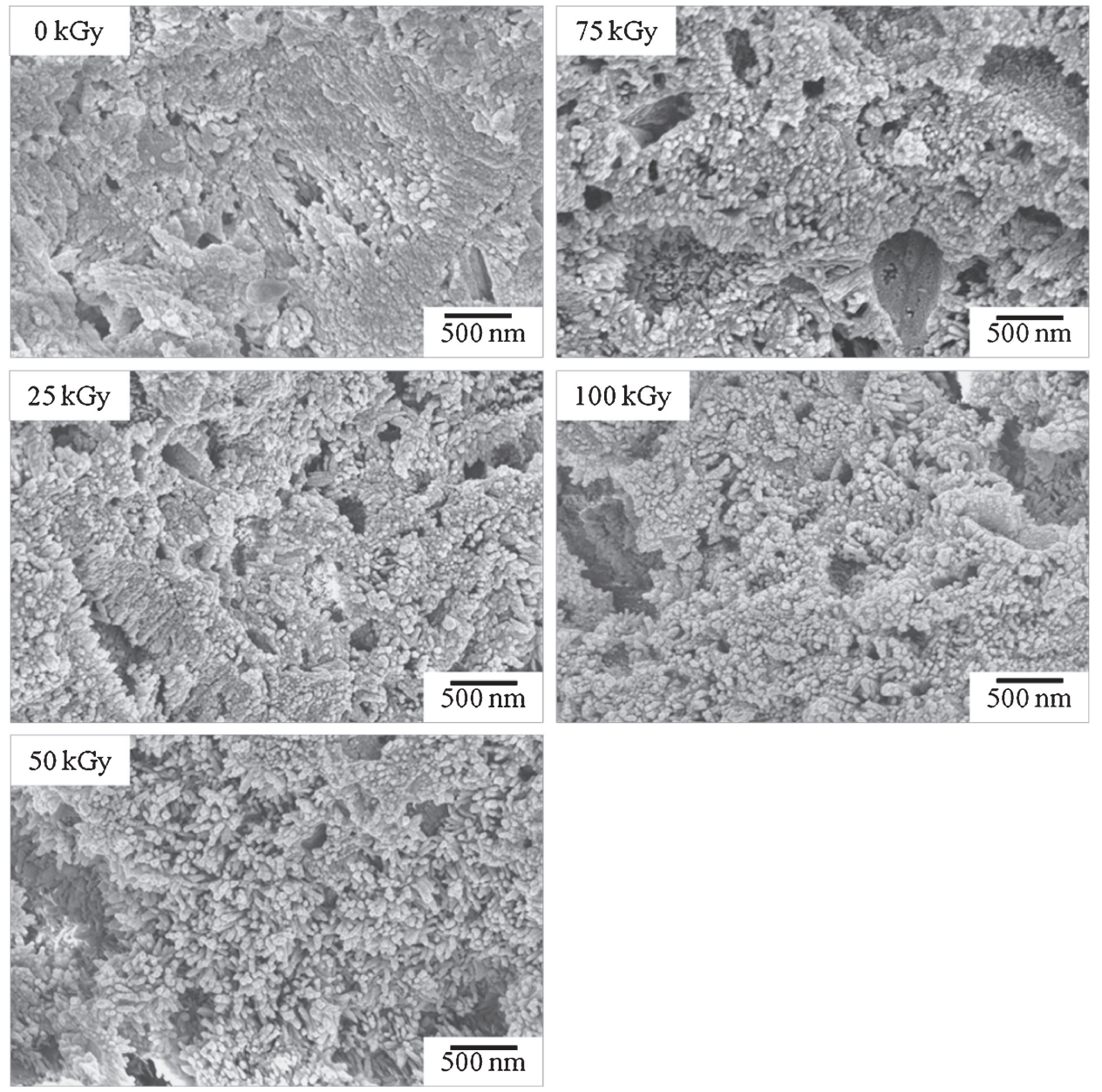

Fig. 9 Scanning electron micrographs of TTCP/DCPA/CSH cement prepared from powders sterilized with different $\gamma$-ray doses immersed in Hanks' solution for 1 day.

crystals (as confirmed by XRD analysis) and micropores of different sizes. Compared to the $\gamma$-ray-sterilized samples, the non-sterilized cement showed a fracture surface morphology that is smoother and denser.

As mentioned earlier, the strength of a CPC is often determined by multiple factors, such as apatite content, ${ }^{26}$ ) porosity level ${ }^{5)}$ and cement morphology. ${ }^{27)}$ Since the $\gamma$-raysterilized and non-sterilized samples of the present study had similar porosity values, the observed higher strength in nonsterilized samples is considered primarily due to their denser morphology and aforementioned higher apatite conversion ratio.

\section{Conclusions}

(1) At a dosage of $25 \mathrm{kGy}$, the working time and setting time of the $\gamma$-ray-sterilized TTCP/DCPA/CSH cement did not show significant changes. At $50 \mathrm{kGy}$ or higher, both significantly decreased.

(2) A dose of $25 \mathrm{kGy}$ caused the 1-d compressive strength of the cement to decrease by $15 \%$. Further increases in $\gamma$-ray dose did not significantly change the strength.

(3) After mixing of powder and setting solution, the $\mathrm{pH}$ values of both sterilized and non-sterilized samples slightly dropped and, after that, both continued to increase with immersion time. After about $20 \mathrm{~min}$, the
$\mathrm{pH}$ values of all non-sterilized and $\gamma$-ray-sterilized samples became stabilized within a narrow range of 8.6-8.8. After immersion in Hanks' solution for 1 day, the $\mathrm{pH}$ values of all non-sterilized and sterilized samples fell to 7.6-8.0.

(4) The XRD patterns of non-sterilized and sterilized powders were substantially similar. After immersion for 1 day, TTCP phase was still distinguishable, while CSH peaks were largely diminished and apatite phase became dominant. The non-sterilized sample had a significantly higher apatite conversion ratio than those of $\gamma$-ray-sterilized samples.

(5) The average 1-d porosity values of all sterilized and non-sterilized samples were similar (31-33\%).

(6) The $\gamma$-ray-sterilized cement samples had coralline type morphology with numerous tiny apatite crystals and micropores. Compared to the sterilized samples, the non-sterilized cement showed a smoother and denser morphology.

\section{Acknowledgment}

The authors would like to acknowledge the support for this research by the Southern Taiwan Science Park (Kaohsiung Science Park), Taiwan, ROC under the Research Grant \# BZ07-18-43-98. 


\section{REFERENCES}

1) S. V. Dorozhkin: Glass. Ceram. 64 (2007) 442-447.

2) V. A. Dubok: Powder Metall. Met. Ceram. 39 (2000) 381-394.

3) H. Schliephake, R. Gruber, M. Dard, R. Wenz and S. Scholz: J. Biomed. Mater. Res. A. 69A (2004) 382-390.

4) P. F. Heini and U. Berlemann: Eur. Spine J. 10 (2001) S205-S213.

5) M. Bohner: Injury 31 (2000) D37-D47.

6) M. V. Thomas and D. A. Puleo: J. Biomed. Mater. Res. B. 88 (2009) $597-610$

7) H. Oda, K. Nakamura, T. Matsushita, S. Yamamoto, H. Ishibashi, T. Yamazaki and S. Morimoto: J. Orthop. Sci. 11 (2006) 167-174.

8) G. D. Brown, B. L. Mealey, P. V. Nummikoski, S. I. Bifano and T. C. Waldrop: J. Periodontol. 69 (1998) 146-157.

9) L. Comuzzi, E. Ooms and J. A. Jansen: Clin. Oral. Implants Res. 13 (2002) 304-311.

10) G. R. Holyoak, S. Wang, Y. Liu and T. D. Bunch: Toxicology 108 (1996) 33-38.

11) K. L. Lin, C. P. Ju and J. H. Chern Lin: J. Mater. Sci. 40 (2005) 2631 2634.

12) M. Takechi, Y. Miyamoto, K. Ishikawa, T. Toh, T. Yuasa, M. Nagayama and K. Suzuki: Biomaterials 19 (1998) 2057-2063.

13) B. Flautre, C. Delecourt, M. C. Blary, P. Van Landuyt, J. Lemaître and P. Hardouin: Bone 25 (1999) 35S-39S.

14) B. R. Constantz, B. M. Barr, I. C. Ison, M. T. Fulmer, J. Baker, L. McKinney, S. B. Goodman, S. Gunasekaren, D. C. Delaney, J. Ross and R. D. Poser: J. Biomed. Mater. Res. 43 (1998) 451-461.

15) D. G. Campbell and P. Li: Aust. N. Z. J. Surg. 69 (1999) 517-521.

16) I. C. Wang, C. P. Ju and J. H. Chern Lin: Mater. Trans. 46 (2005) 17011705.

17) C. P. Ju, S. H. Hung, C. K. Chen, W. L. Chen, J. W. Lee, R. M. Lin, W. C. Chen and J. H. Chern Lin: Mater. Chem. Phys. 130 (2011) 303308 .

18) J. H. Chern Lin, S. Y. Yu, C. K. Chen, W. L. Chen, J. W. Lee, R. M. Lin and C. P. Ju: Mater. Trans. 52 (2011) 1949-1953.

19) J. H. Chern Lin, S. H. Hung, W. L. Chen, C. K. Chen, J. W. Lee, R. M. Lin and C. P. Ju: J. Med. Biol. Eng. 32 (2012) 201-204.

20) W. E. Brown and E. F. Epstein: J. Res. Natl. Bur. Stand. Sect. A: Phys. Chem. 69A (1965) 547-551.

21) D. C. Mears: Int. Met. Rev. 22 (1977) 119-155.

22) Y. Fukase, E. D. Eanes, S. Takagi, L. C. Chow and W. E. Brown: J. Dent. Res. 69 (1990) 1852-1856.

23) C. H. Tsai, J. H. Chern Lin and C. P. Ju: J. Biomed. Mater. Res. B. Appl. Biomater. 80B (2007) 244-252.

24) L. Xie and E. A. Monroe: Mater. Res. Soc. Symp. Proc. 179 (1989) 25-39.

25) K. Ishikawa, S. Takagi, L. C. Chow and Y. Ishikawa: J. Mater. Sci. Mater. Med. 6 (1995) 528-533.

26) Y. Takezawa, Y. Doi, S. Shibata, N. Wakamatsu, H. Kamemizu, T. Goto, M. Iijima, Y. Moriwaki, K. Uno, F. Kubo and Y. Haeuchi: J. Jpn. Soc. Dent. Mater. 6 (1988) 426-431.

27) L. E. Carey, H. H. K. Xu, C. G. Simon, S. Takagi and L. C. Chow: Biomaterials 26 (2005) 5002-5014. 